\title{
Comparison between PI and PR Current Controllers of a Grid- Connected Photovoltaic System under Load Variation
}

\author{
Soukaina Essaghir, Mohamed Benchagra, Noureddine El barbri \\ National School of Applied Sciences, ISERT Laboratory, ENSA -Khouribga, Hassan $1^{\text {st }}$ University, Morocco
}

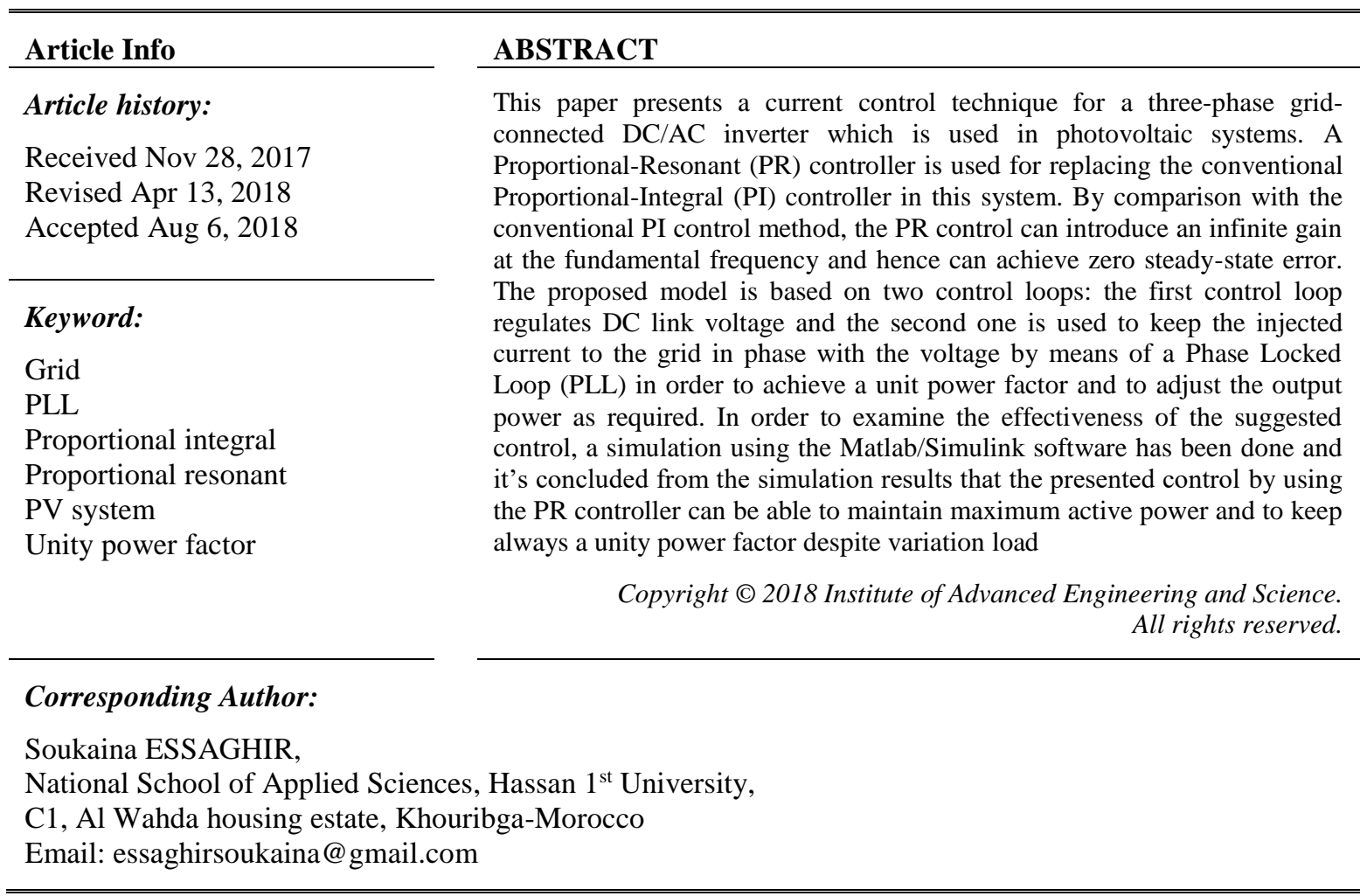

\section{INTRODUCTION}

In the present scenario of world energy sector, renewable sources are growing their importance day by day. Nowadays, more and more interest of photovoltaic (PV) energy has been focused on interconnection between the PV power systems and the grid. The connection of the photovoltaic system to the grid generates a phase shift between the voltage and the current injected into grid, and moreover, during a variation load, fluctuations appear in the voltage and in the output power and the studied system becomes unstable. For this reason, we need a power factor control which allows the achievement of unity power factor and the adjustment of the output power as required $[1,2]$.

Generally, the grid-connected PV power systems mainly consist of a boost DC/DC converter and a DC/AC inverter. The DC/AC inverter is considered as the core of the whole system because of an important role in grid-connected operation, for this reason the current controller can have a significant effect on the quality of the current supplied to the grid by the PV inverter, therefore, it is important that the controller provides a high quality sinusoidal output by limiting the harmonics generated by these inverters in order to ovoid the adverse effects on the grid power quality. Two controllers which are used in current controlled PV inverters are the coventionnal PI controller and the PR controller. The purpose of this work is focused on a comparison between PI and PR current controllers of a Grid-Connected Photovoltaic System Under Load Variation [3]. The rest of this paper is organized as follows. Section 2 introduces some informations on the studied system. Section 3, develop the overall control schemes for both types of controllers (PI and PR controllers). Then, the obtained results using Matlab/Simulink are presented in section 4. Finally, conclusion is giving in section 5 . 


\section{DESCRIPTION OF THE STUDIED SYSTEM}

In this paper, the design of a three-phase grid connected PV inverter is presented. The PV array used consists of 66 strings of 5 series-connected modules connected in parallel. A DC-DC Boost converter and a three-level voltage inverter are used to provide the flexibility of the system and the quality of the generated waves. The connection between the generator and the DC bus of the inverter require an interface to adapt the levels of variation of the voltage and the current between these two devices. Controlling the generated power requires varying the amplitude of the voltage at the ends of the generator, without changing the voltage at the DC bus. The three-level Voltage Source Inverter (VSI) regulates DC bus voltage and keeps unity power factor under variation load. In fact, the control system uses two control loops, an external control loop which regulates DC link voltage and an internal loop which regulates active and reactive currents components (Id and Iq). The output voltage of the converter and the inverter is controlled by the PWM modulator [4-10]. The principal specifications for this system are given in Table 1.

\section{ACTIVE AND REACTIVE POWER CONTROL}

\subsection{PV Power Calculation}

The concept of this type of control is to impose the active and reactive power values injected into grid in order to keep unity power factor. By acting on the PWM control, the control loops, must impose the instantaneous values of the currents delivered by the inverter $\left(i_{01}, i_{02}, i_{03}\right)$ in such a way that the currents supplied by the grid $\left(i_{a}, i_{b}, i_{c}\right)$ become sinusoidal and in phase with the corresponding single voltages $\left(\mathrm{V}_{\mathrm{a}}, \mathrm{V}_{\mathrm{b}}, \mathrm{V}_{\mathrm{c}}\right)$ [11]. We describe the active and reactive power of the three-phase grid-connected VSI in the Park reference $(\mathrm{d}, \mathrm{q})$, we obtain the following equations:

$$
\begin{aligned}
& P=\frac{3}{2}\left(V_{d} \cdot i_{d}+V_{q} \cdot i_{q}\right) \\
& Q=\frac{3}{2}\left(V_{d} \cdot i_{q}-V_{q} \cdot i_{d}\right)
\end{aligned}
$$

We suppose that the three-phase grid voltage is ideally sinusoidal then, the grid voltage vector in the $\mathrm{d}, \mathrm{q}$ frame is given by the following equations:

$$
\begin{aligned}
& V_{d}=V \\
& V_{q}=0
\end{aligned}
$$

Consequently, equations (1) and (2) can be rewritten as (5) and (6):

$$
\begin{aligned}
& P=\frac{3}{2}\left(V_{d} \cdot i_{d}\right) \\
& Q=\frac{3}{2}\left(V_{d} . i_{q}\right)
\end{aligned}
$$

We note from the last equation that the active power depends on the d-axis current, and the reactive power depends on the q-axis current. Furthermore, to achieve unity power factor, the q component of the command current vector is should be set to zero. The relation ship between the instantaneous active power exchanged between the PV array and the grid in the event of a lossless power transmission between the two is given by (7):

$$
P_{p v}=P=\frac{3}{2}\left(V_{d} . i_{d}\right)
$$

\subsection{DC bus voltage regulation}

The regulation of DC bus voltage is effected by absorbing or supplying the active power to the electrical grid. In the DC voltage loop, we regulate the Vdc voltage to a constant value which is Vdc_ref, the 
error is defined as the difference between the measured voltage Vdc and the reference voltage Vdc_ref, $(e=$ $V d c-$ Vdc_ref) [12,13]. In the case where a PI corrector is used, the output of this corrector is the reference of the direct component of the current injected into grid Id_ref as show in figure 1.

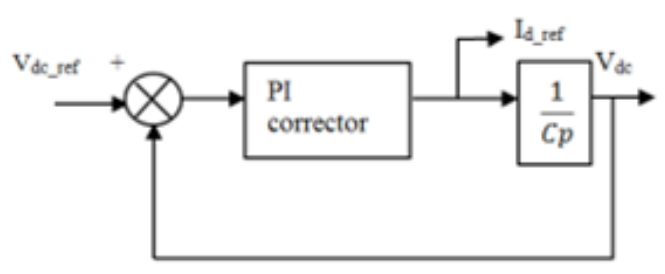

Figure 1. DC bus voltage control loop

The closed-loop transfer function of $\mathrm{dc}$ voltage regulation, obtained from figure 1 , has the following form:

$$
\frac{V_{d c}}{V_{d c_{-} r e f}}=\frac{1+\frac{K_{p}}{K_{i}} p}{1+\frac{K_{p}}{K_{i}} p+\frac{c}{K_{i}} p^{2}}
$$

The damping ratio $\frac{2 \xi}{\omega_{n}}=\frac{K_{p}}{K_{i}}$ and $\frac{1}{\omega_{n}{ }^{2}}=\frac{c}{K_{i}}$. Thus, the parameters of the voltage regulator can be designed as follows:

$$
\begin{aligned}
& K i=c . \omega_{n}{ }^{2} \\
& K p=2 \xi . c . \omega_{n}
\end{aligned}
$$

\subsection{Synchronisation of the PV pannel with grid}

The synchronization control over the evolution of the network voltages is based on the three-Phase Locked Loop. It consists to apply an inverse Park transformation on the phase voltages of the grid. The q-axis component generated by this transformation is locked to zero by acting on the angle of the Park reference in order to generate the synchronization angle $\theta$.

When the difference between grid phase angle $\theta \mathrm{r}$ and the inverter phase angle $\theta$ is reduced to zero $(\Delta \theta=(\theta \mathrm{r}-\theta)=0)$, the PLL became active $[14,15]$.

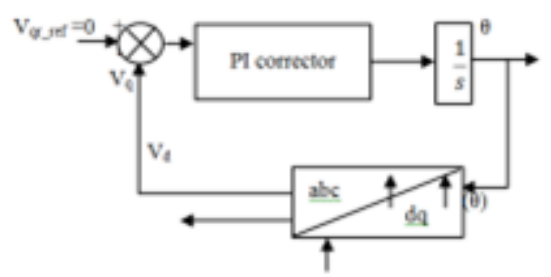

Figure 2. Block diagram of PLL

\subsection{Current control}

\subsubsection{PI Controller Design}

To connect the voltage inverter in parallel with the grid and make it works as a power source, we consider an inverter connected to grid, via resistor $\mathrm{R}$ and inductance L [16]. The equivalent three-phase system in terms of fundamental component is shown in Figure 3.

Comparison between PI and PR Current Controllers of a Grid-Connected... (Soukaina Essaghir) 


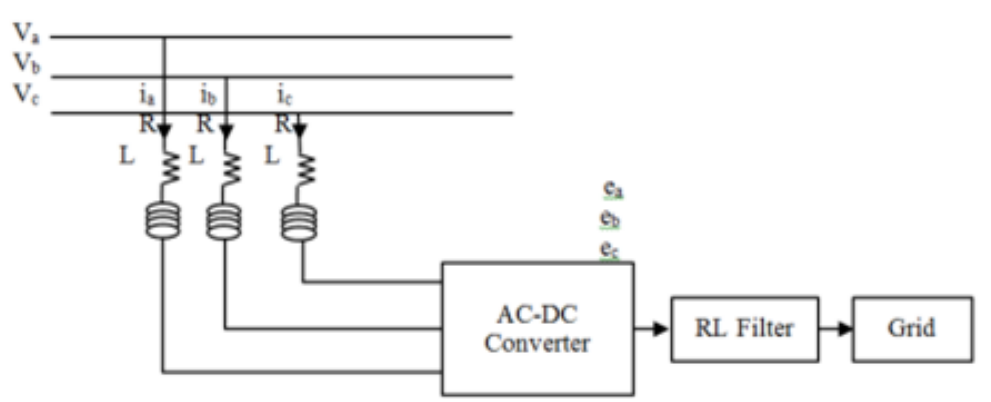

Figure 3. Diagram of an inverter connected to grid

Using Park transformation, the components of the active and reactive current are given by (9):

$$
\frac{d}{d t}\left[\begin{array}{l}
i_{d} \\
i_{q}
\end{array}\right]=\left[\begin{array}{cc}
-\frac{R}{L} & \omega \\
\omega & -\frac{R}{L}
\end{array}\right]\left[\begin{array}{l}
i_{d} \\
i_{q}
\end{array}\right]+\frac{1}{L}\left[\begin{array}{l}
V_{d}-e_{d} \\
V_{q}-e_{q}
\end{array}\right]
$$

Furthermore, by using PI-type regulators, a fast-dynamic response and zero steady-state errors can be achieved. The two new variables presented in (10) present are the outputs of the control system consisting of two PI controllers:

$$
X_{1}=\frac{1}{L}\left(V_{d}-e_{d}\right) \& X_{2}=\frac{1}{L}\left(V_{q}-e_{q}\right)
$$

The values of $i_{\text {dref }}$ and $i_{\text {qref }}$ are the references of the active and reactive currents:

$$
\begin{aligned}
& X_{1}=\left(i_{\text {dref }}-i_{d}\right)\left(K_{p}+\frac{K_{i}}{p}\right)-\omega i_{q} \\
& X_{2}=\left(i_{\text {qref }}-i_{q}\right)\left(K_{p}+\frac{K_{i}}{p}\right)+\omega i_{d}
\end{aligned}
$$

We apply the Laplace transformation to (9), (10), (11), (12). We obtain the closed-loop transfer function of current loops as shown in (13):

$$
F(p)=\frac{i_{d}}{i_{\text {dref }}}=\frac{i_{q}}{i_{\text {qref }}}=\frac{1+p \frac{K_{p}}{K_{i}}}{1+p \frac{K_{p}+\frac{R}{L}}{K_{i}}+\frac{p^{2}}{K_{i}}}
$$

The damping ratio $\frac{2 \xi}{\omega_{n}}=\frac{K_{p}+\frac{R}{L}}{K_{i}}$ and $\frac{1}{\omega_{n}{ }^{2}}=\frac{1}{K_{i}}$ Thus, the parameters of the current regulator can be designed as follows [17]:

$$
\begin{aligned}
& K i=\omega n^{2} \\
& K p=2 \xi \omega n-\frac{R}{L}
\end{aligned}
$$




\subsubsection{PR Controller Design}

The PR current controller $\mathrm{G}_{\mathrm{PR}}(\mathrm{s})$ is represented by the following equation :

$$
G_{P R}=K_{P}+K_{I} \frac{s}{s^{2}+\omega_{0}^{2}}
$$

Where, $K_{I}$ is the integral gain term, $\omega_{0}$ is the resonant frequency $[18,19]$ and $K_{P}$ is the proportional gain term, it determines the dynamics of the system; bandwidth, phase and gain margins. The ideal resonant term on its own in the PR controller provides an infinite gain at the ac frequency $\omega_{0}$ and no phase shift and gain at the other frequencies as presented in [20].

Unfortunately, the ideal PR controller acts like a network with an infinite quality factor, which is hard to implement the PR controller in reality. Firstly, the infinite gain introduced by PR controller leads to an infinite quality factor which cannot be achieved in either analog or digital system.

Secondly, the gain of PR controller is much reduced at other frequencies and it is no adequate to eliminate harmonic influence caused by grid voltage. For these reason, in our study we chose an approximating ideal (non-ideal) PR controller which is given by (8), using a high-gain low-pass filter to solve the problems mentioned above.

Equation (12) represents an ideal PR controller which can give stability problems because of the infinite gain. To avoid these problems, the PR controller can be made non-ideal by introducing damping as shown in (13) below:

$$
G_{P R}=K_{P}+K_{I} \frac{2 \omega_{.} s}{s^{2}+2 \omega_{c} . s+\omega_{0}^{2}}
$$

Where, $\omega_{\mathrm{c}}$ is the bandwidth around the ac frequency of $\omega_{0}$. With (13) the gain of the PR controller at the ac frequency $\omega_{0}$ is now finite but it is still large enough to provide only a very small steady state error. This equation also makes the controller more easily realizable in digital systems due to their finite precision [21-23].

The frequency response of (12) is shown in Fig. 4(a), unfortunately, the ideal PR controller acts like a network with an infinite quality factor, which is hard to implement the PR controller in reality. Firstly, the infinite gain introduced by PR controller leads to an infinite quality factor which cannot be achieved in either analog or digital system. Secondly, the gain of PR controller is much reduced at other frequencies and it is no adequate to eliminate harmonic influence caused by grid voltage. The frequency response of (13) is shown in Figure 4(b), where the resonant peak now has a finite gain of $40 \mathrm{~dB}$ which is satisfactorily high for eliminating the voltage tracking error [24].

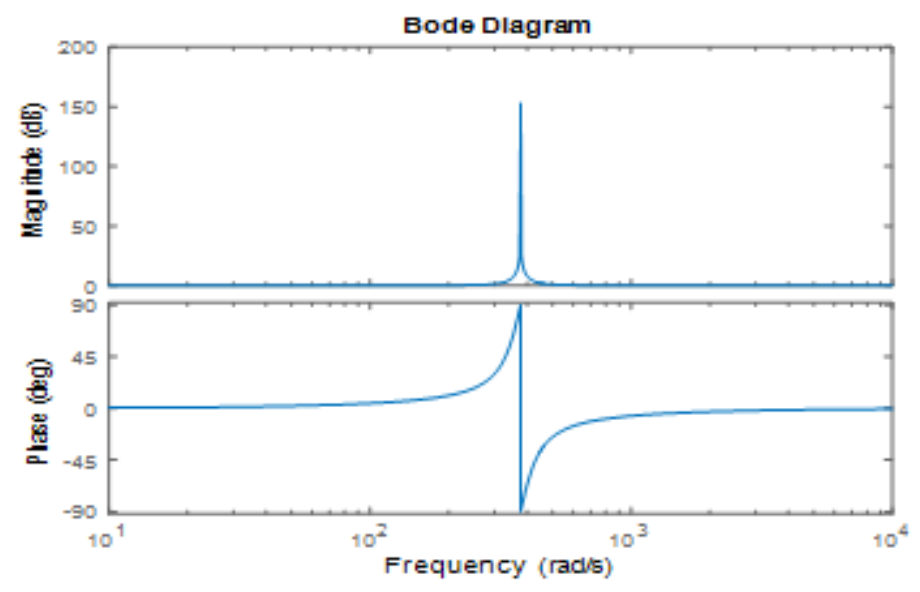

Figure 4.a. Frequency responses of an ideal $\mathrm{PR}$ controller with $\mathrm{Kp}=1, \mathrm{Ki}=100$. 


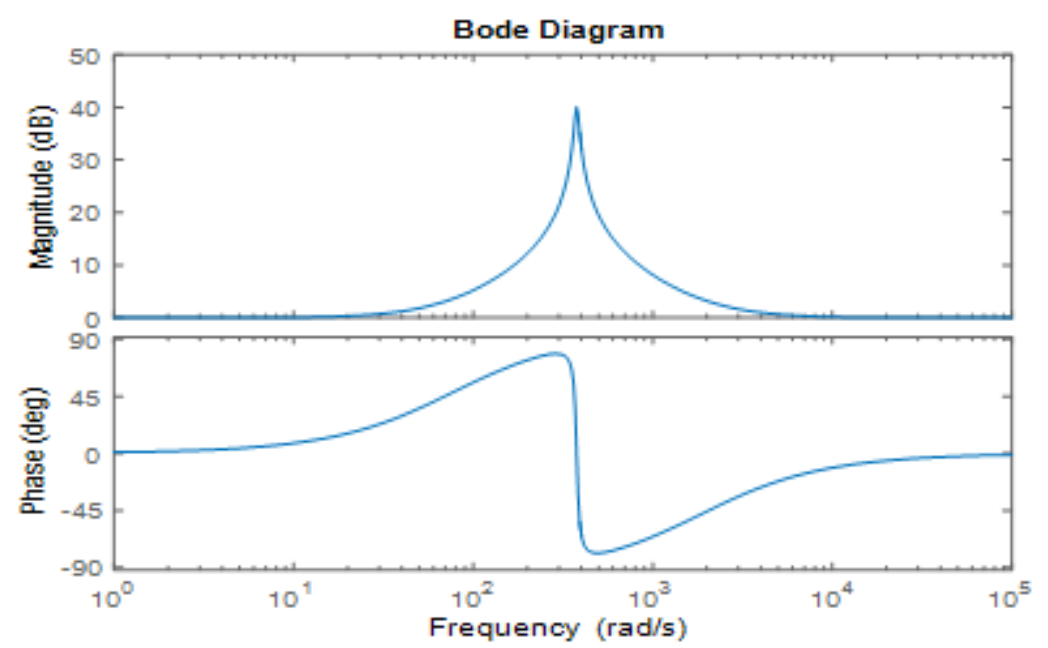

Figure 4.b. Frequency responses of a non-ideal PR controller with $\mathrm{Kp}=1, \mathrm{Ki}=100, \omega_{\mathrm{c}}=10(\mathrm{rad} / \mathrm{s})$.

\section{RESULTS AND ANALYSIS}

The obtained results using Matlab/Simulink are discussed in this section, Figure 5 shows the full detailed model which contains a PV array delivering to the grid a maximum power of $100 \mathrm{~kW}$ at $1000 \mathrm{~W} / \mathrm{m} 2$ sun irradiance.

The detailed model contain:

a. PV array delivering a maximum power of $100 \mathrm{~kW}$ at $1000 \mathrm{~W} / \mathrm{m} 2$ sun irradiance.

b. Boost converter increases voltage from PV voltage (273.5 VDC at maximum power) to 500 VDC

c. Switching duty cycle of the boost converter is optimized by the MPPT controller that uses the P\&O technique.

d. $1980 \mathrm{~Hz}$ three-level three-phase VSI. The VSI converts the 500 VDC link voltage to 260 VAC and keeps unity power factor.

e. Current regulator which provide a unity power factor using the PI and PR regulators.

f. $100 \mathrm{kVA}, 260 \mathrm{~V} / 25 \mathrm{kV}$ three-phase coupling transformer.

g. Grid specifications ( $25 \mathrm{kV}$ distribution feeder and $120 \mathrm{kV}$ equivalent transmission system).

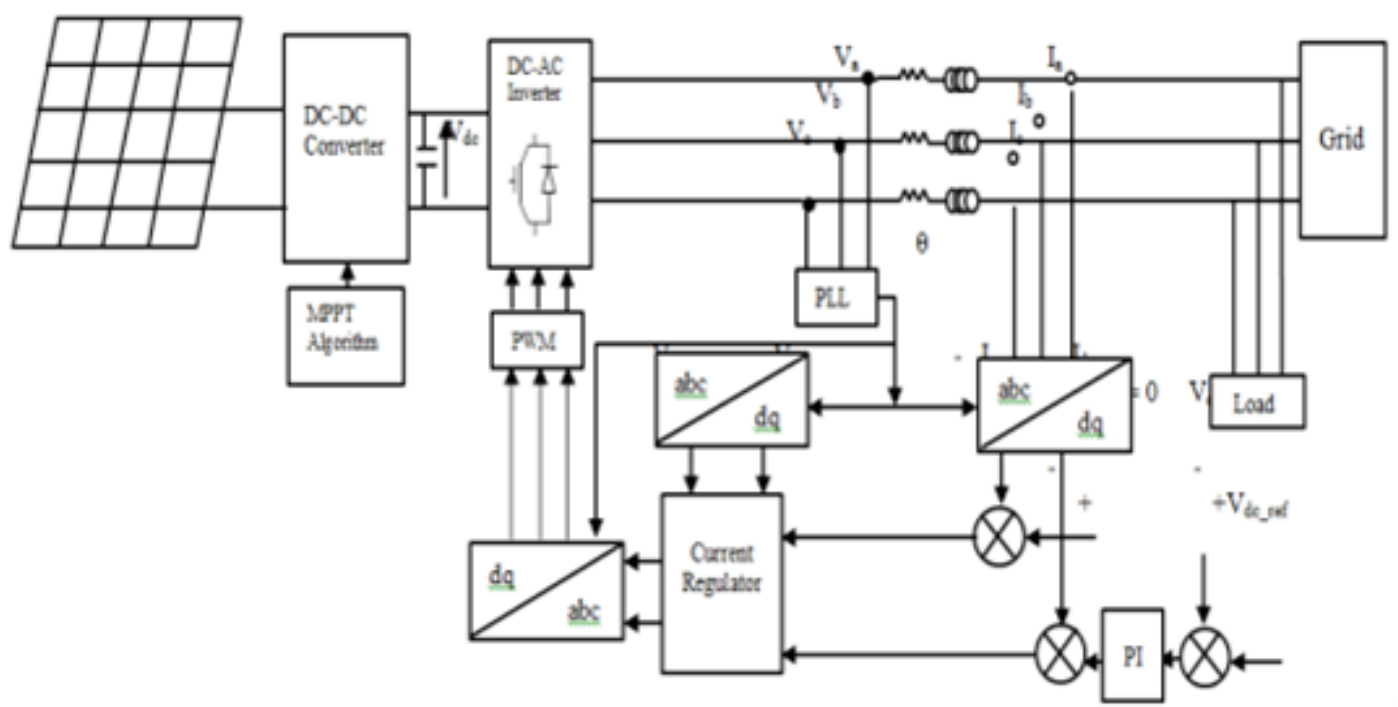

Figure 5. Full detailled model and control using Matlab/Simulink 
Figure 6 shows that the voltage and current injected to grid are in phase, which explains the single injection of the active power, and according to Figure 7 we notice that the reactive power is zero and that the active power reaches its maximum value $(96.14 \mathrm{~kW})$ which means that the simulation has given us the expected results and the control that we have established makes it possible to have a unity power factor.

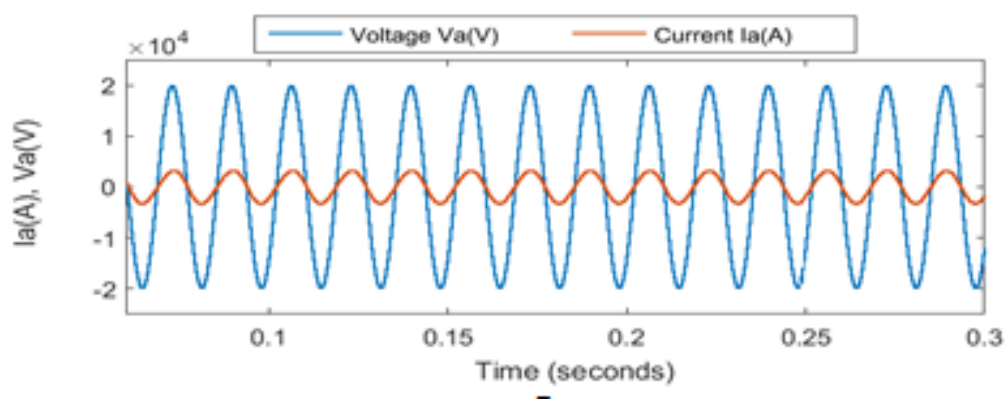

Figure 6. Line to line voltage and current injected into grid

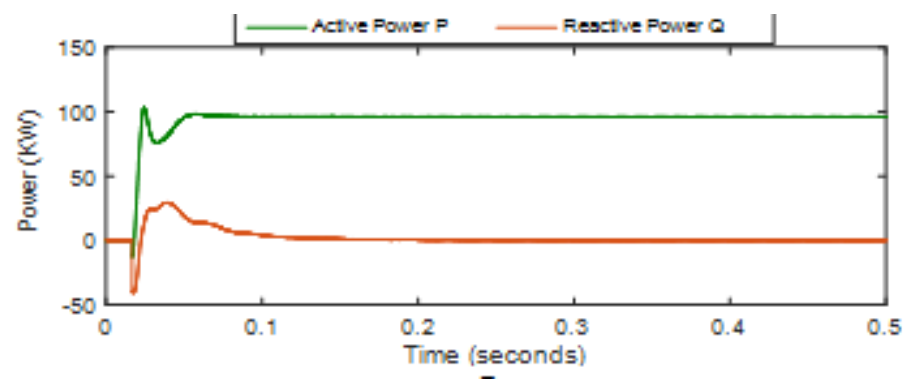

Figure 7. Characteristic of active and reactive power injected into grid

Figure 8.a and Figure 8.b show the frequency analysis of the grid current and its THD value by using the PI and PR controller, respectively. The simulation results show that the THD of the PR controller is much less than that of the PI controller, consequently the PR controller can track the sinusoidal reference and mitigate the harmonics better than PI controller which explain the high performance of this type of controller.

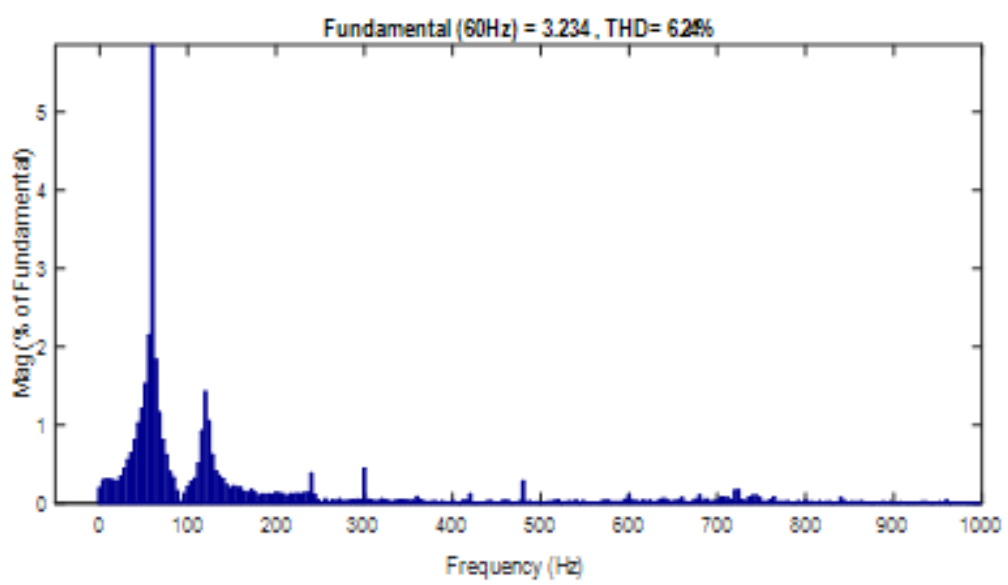

Figure 8.a. FFT analysis and THD value of grid current by using PI controller 


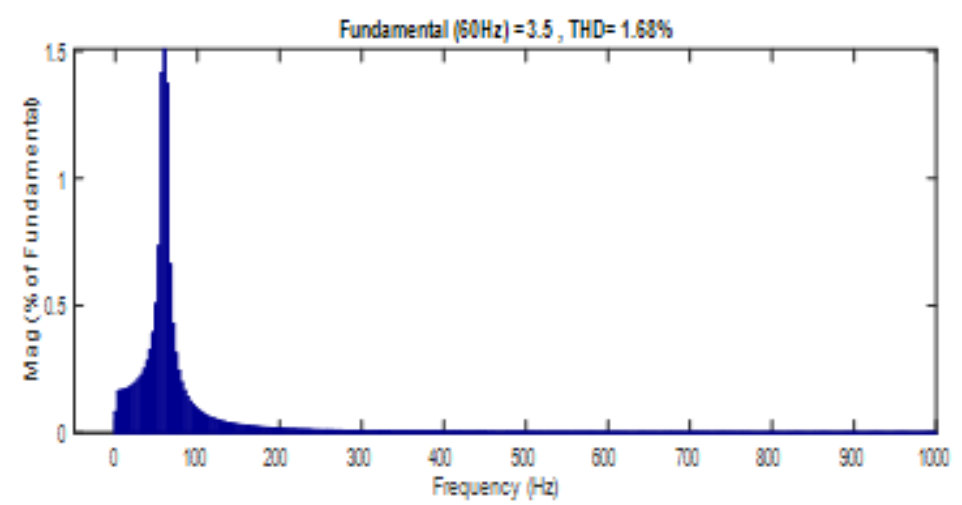

Figure 8.b. FFT analysis and THD value of grid current by using PR controller

Using a PI regulator, Figure 9.a shows that, after the addition of the inductive load at time $\mathrm{t}=0.3 \mathrm{~s}$, the current injected into grid becomes in phase delay compared to the voltage but after a few milliseconds, the two quantities $\mathrm{V}$ and I become in phase, unlike when using a PR regulator, as shown in Figure 9.b, the current and the voltage is always in phase despite the addition of the inductive load. For this reason, this figure shows the importance of the choice of this type of corrector in order to ensure a synchronization between the voltage and the current injected into grid despite the addition of the inductive load.

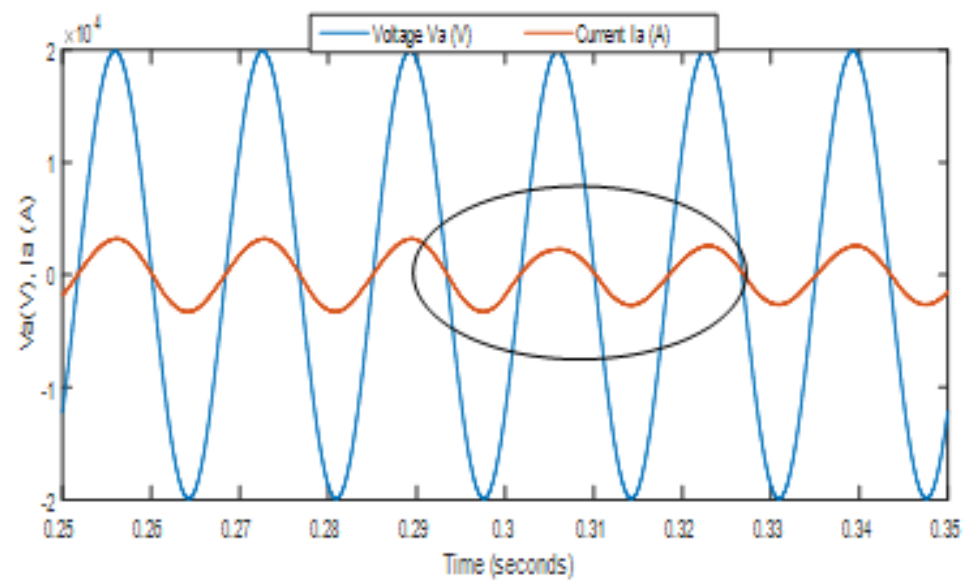

(a)

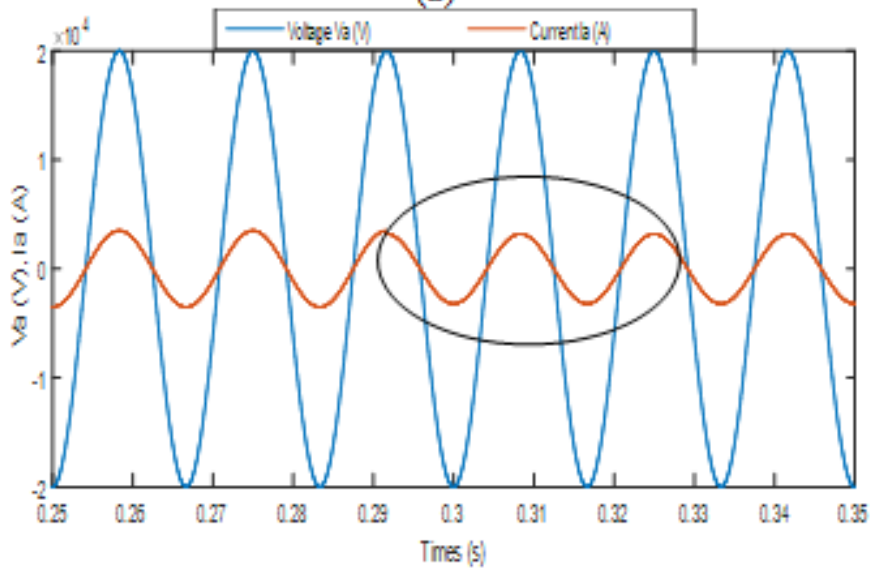

(b)

Figure 9. Voltage and current injected to grid with variation load by using a: PI controller, b: PR controller 
Similarly, the Figure 10 shows that when using a PI corrector, and at the moment when the inductive charge is added $(\mathrm{t}=0.3 \mathrm{~s})$, the reactive power $\mathrm{Q}$ becomes positive and after a few milliseconds it retains its initial value, but using the corrector PR, the reactive power always keeps its value which is equal to zero which explains the high performance of this type of corrector and its ability to maintain a single injection of the active power and to keep always a unity power factor despite variation load.

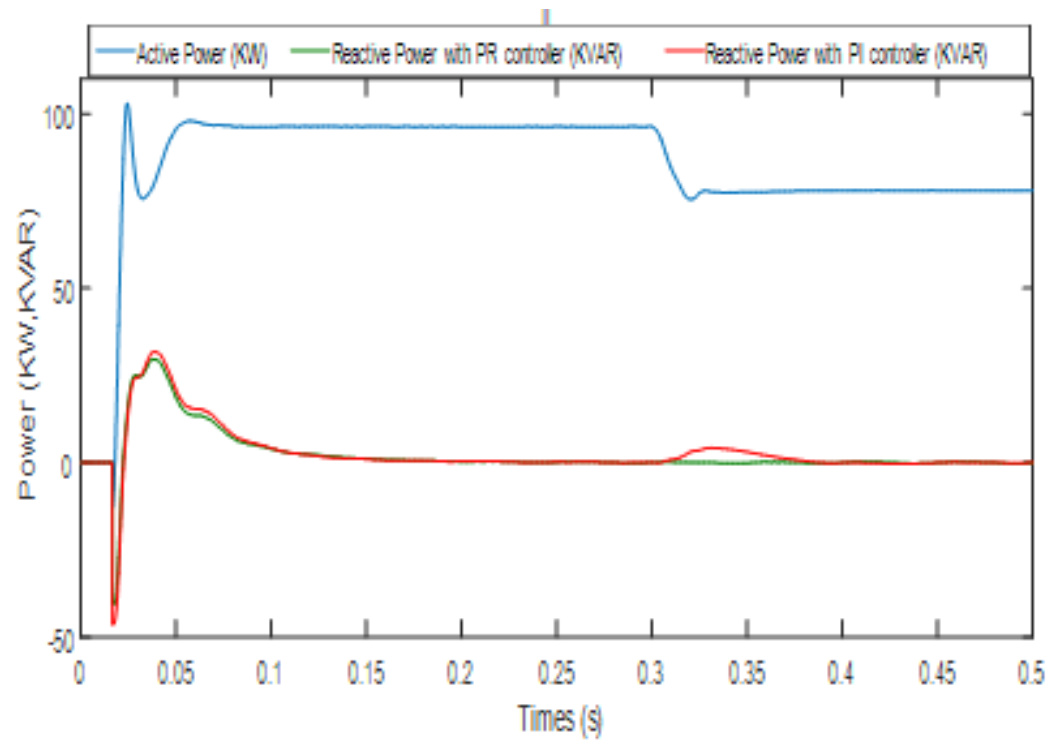

Figure 10. Active and reactive power with variation load by using PI ad PR controller

For this purpose, the simulation shows the importance of the proposed work and gave us the expected results. Therefore, and compared to other researches [11,24], the PR corrector proposed allows us to have a unit power factor despite the addition of the reactive load and especially without influencing the pace of the reactive power and without introducing any instantaneous phase difference between the voltage and the current injected into grid.

\section{CONCLUSION}

This paper has presented a comparison between standard PI and PR current controllers in gridconnected PV systems. After the modeling of the three-phase grid connected PV systems and the power factor control schemes, the obtained results are very important and satisfactory. They show that the proposed model with the PR controller correctly describes the dynamic performance of the PV system studied. The PR corrector can track the sinusoidal reference and mitigate the harmonics better than PI controller, moreover, the PR corrector allows us to have a unit power factor despite the addition of the reactive load and especially without influencing the pace of the reactive power and without introducing any instantaneous phase difference between the voltage and the current injected into grid.

\section{APPENDIX}

Table 1. Photovoltaic Parameters

\begin{tabular}{lccc}
\hline Temperature & $\mathrm{T}$ & 25 & ${ }^{\circ} \mathrm{C}$ \\
Open circuit voltage & $V_{o c}$ & 64.2 & $\mathrm{~V}$ \\
Short circuit current & $I_{s c}$ & 5.96 & $\mathrm{~A}$ \\
Voltage, maximum power & $V_{\max }$ & 54.7 & $\mathrm{~V}$ \\
Current, maximum power & $I_{\max }$ & 5.58 & $\mathrm{~A}$ \\
Maximum power & $P_{\max }$ & 305 & $\mathrm{~W}$ \\
\hline
\end{tabular}




\section{REFERENCES}

[1] H. Liu, S. Jiang, W. Wang and D. Xu, "The maximum Power Point Tracking Based on the Double Index Model of PV Cells ", IEEE,IPEMC, 2009.

[2] G.V. Marcelo, G. Jonas and RF. Ernesto, "Comprehensive Approach to Modeling and Simulation of Photovoltaic Arrays," IEEE Transactions on Power Electronics, 24, 2009,p. 4.

[3] M. Ciobotaru, R. Teodorescu, F. Blaabjerg, "Control of a Single-Phase PV Inverter”, EPE2005, Dresden, 2005.

[4] V. Khanna, B.K. Das, D. Bisht, "MATLAB/Simelectronics models based study of solar cells, " In International Journal of Renewable Energy Research, Vol.3, No.1, 2013.

[5] W. Rezgui, L.H. Mouss, M.D. Mouss, "Modeling of a photovoltaic field in malfunctioning," In Control, Decision and Information Technologies (CoDIT), 2013 International Conference.

[6] H. Ouatman, M. Ouassaid, M. Cherkaoui, "Modeling and Control of a Grid-Connected PV Energy Conversion System," IEEE, WSEAS Transactions on Systems and Control, ISSN: 2224-2856, Vol 10, 2015.

[7] A.H. Mollah, G.K. Panda, P.K. Saha, "Three Phase Grid Connected Photovoltaic System with Maximum Power Point Tracking," In International Journal of Advanced Research in Electrical, Electronics and Instrumentation Engineering, ISSN: 2278 - 8875, Vol. 4, Issue 5, May 2015.

[8] S. Juing-huei, C. Chao-Liang, C. Jiann-Jong and W. Chien-Ming, "Simulink Behavior Models For DC-DC Switching Converter Circuits Using PWM Control ICs”, International Journal of Engineering Education, 2006, pp. 315-322,vspace-7pt.

[9] W. Tsai-Fu, N. Hung-Shou, S. Chich-Lung and C. Tsung-Ming, "A Single-Phase Inverter System for PV Power Injection and Active Power Filtring With Nonlinear Inductor Consideration”, IEEE Transactions On Industrial Electronics, 2005, pp. 1075-1083.

[10] Z. Bin Ibrahim, M. L. Hossain, I. Bin Bugis, J. M. Lazi, N. M. Yaakop, "Comparative Analysis of PWM Techniques for Three Level Diode Clamped Voltage Source Inverter," International Journal of Power Electronics and Drive System, Vol. 5, No. 1, pp. 15-23 ISSN: 2088-8694, July 2014.

[11] S. Essaghir, M. Benchagra, N. El Barbri, "Power Factor Control of a Photovoltaic System Connected to Grid Under Load Variation," Interational Conference on Electrical and Information Technologies, November 15-18, 2017, Morocco.

[12] R. Kadri, J. P. Gaubert, Member IEEE, G. Champenois, Member IEEE, “ An Improved Maximum Power Point Tracking for Photovoltaic Grid-Connected Inverter Based on Voltage-Oriented Control,” IEEE Trans. Industrial Electronics, Vol. 58, No. 1, Januray 2011.

[13] R. Balasubramanian, S. palani, "Simulation and Performance Evaluation of Shunt Hybrid Power Filter for Power Quality Improvement Using PQ Theory,” International Journal of Electrical and Computer Engineering, Vol. 6, No. 6, pp. 2603-2609, ISSN: 2088-8708, December 2016.

[14] L. Rolim, D. Costa, M. Aredes, "Analysis and software implementation of a robust synchronizing PLL circuit based on the pq theory,",IEEE Trans. Industrial Electronics, Vol. 53, No.6, pp. 1919-1926, 2006.

[15] O. M. Benaissa, S. Hadjeri, S. A. Zidi, "Modeling and Simulation of Grid Connected PV Generation System Using Matlab/Simulink," International Journal of Power Electronics and Drive System, Vol. 8, No. 1, pp. 392-401, ISSN: 2088-8694, March 2017.

[16] E.G. Shahraki, "Apport de l'UPFC à l'amélioration de la stabilité transitoire des réseaux électriques," Doctoral thesis, Henri Poincaré Nancy-I Universit, 2003.

[17] M. Messaoud, "Modélisation et optimisation de systèmes de production d'énergies renouvelables couplés au réseau," Doctoral thesis, Mentouri de Constantine University, 2012.

[18] D. Zammit, C.S. Staines, M. Apap, 'Comparison between PI and PR Current Controllers in Grid Connected PV Inverters, " World Academy of Science, Engineering and Technology International Journal of Electrical, Computer, Energetic, Electronic and Communication Engineering Vol:8, No:2, 2014.

[19] S.M. devi1, Dr.K.Punitha, "Resonant Current Controller Based THD Reduction In AC Micro Grid" International Journal of Emerging Technology in Computer Science \& Electronics (IJETCSE) ISSN: 0976-1353 Volume 22 Issue 2 - MAY 2016.

[20] R. Teodorescu, M. Liserre, P. Rodriguez, "Grid Converters for Photovoltaic and Wind Power Systems", Wiley, 2011.

[21] Guo Xiaoqiang, Zhao Qinglin and Wu Weiyang "A Single-Phase Grid-Connected Inverter System With Zero Steady-State Error', in CES/IEEE 5th International Power Electronics and Motion Control Conference, 2006, vol. 1, pp. 1-5, Aug. 2006.

[22] R. Teodorescu; F. Blaabjerg; M. Liserre and P.C. Loh "Proportional resonant controllers and filters for gridconnected voltage-source converters", in IEE Proceedings - Electric Power Applications, vol. 153,iss. 5, pp. 750$762,2006$.

[23] D. N. Zmood, D. G. Holmes, "Stationary Frame Current Regulation of PWM Inverters with Zero Steady-State Error", IEEE Transactions on Power Electronics, Vol. 18, No. 3, May 2003.

[24] H.Cha, J.E.Kim, T.K. Vu "Design and control of Proportional-Resonant controller based Photovoltaic power conditioning system, " IEEE Energy Conversion Congress and Exposition, 2009. ECCE 2009. 